\title{
Fluidized Bed Experiments Using Platinum And Palladium Particles In Heavy Water
}

\author{
M.H. MILES \\ Department of Chemistry, University of La Verne \\ La Verne, CA 91750, USA \\ E-Mail: mmiles@ulv.eduormelmiles1@juno.com
}

\begin{abstract}
These experiments were designed to give the dynamic electrolysis conditions of fluidized beds by the use of small palladium particles. Both direct current electrolysis and pulse power electrolysis methods were used in this study. The excess power observed was $90 \mathrm{~mW}$ for direct current electrolysis in $\mathrm{D}_{2} \mathrm{O}+0.1 \mathrm{M} \mathrm{LiOD}$ ( $\mathrm{I}=0.300$ to $0.400 \mathrm{~A}$ ). For pulse electrolysis (pulse width $1.0 \mu \mathrm{s}$, pulse frequency $5 \mathrm{KH}_{\mathrm{Z}}$, peak voltage $98 \mathrm{~V}$ ), the excess power increased to $250 \mathrm{~mW}$. No excess power was observed for similar experiments using platinum particles in $\mathrm{D}_{2} \mathrm{O}+0.1 \mathrm{M}$ LiOD.
\end{abstract}

\section{Introduction}

Fluidized bed as well as packed bed reactors give increased surface areas and therefore more efficient electrochemical processes. ${ }^{1}$ In fact, Martin Fleischmann, who initiated cold fusion studies, was also one of the innovators in the understanding of these reactor designs. ${ }^{1}$ A fluidized-bed reactor consists of a finely divided electrode material this is distributed over the full electrolyte volume by an ascending liquid or gas flow, and this material continuously collides with special current collector electrodes. ${ }^{2}$ Fluidized bed cell designs, therefore, provide the dynamic conditions that are believed to be important for the observation of excess enthalpy in cold fusion experiments. Furthermore, the many miniature palladium particles make these experiments more independent of the metallurgical properties of any selected palladium cathode.

\section{Calorimetric Design and Cell Modifications}

The basic China Lake calorimetric design where the heat transfer is mainly by conduction was used in this study. ${ }^{3,4}$ The only variation was the use of copper granules rather than aluminum foil in the secondary compartment outside the electrochemical cell (see Fig. 1, Ref. 3). This change was designed to facilitate heat conduction between the electrochemical cell and the bath while minimizing heat transfer out of the top of the cell. Two identical calorimetric cells were used with platinum particles in Cell A as a control while palladium particles were investigated in Cell B. The platinum and palladium particles were miniature cylindrical rods that had the same dimensions ( 0.6 to $0.65 \mathrm{~mm}$ diameters and 0.65 to $0.7 \mathrm{~mm}$ lengths) and the same purity (99.99\%).

Cell calibrations were made by assuming that there was no excess power during the first week of electrolysis at constant current of 0.300 to $0.400 \mathrm{~A}$. This assumption yields a lower-bound value for the heat transfer coefficient. ${ }^{5,6}$ The use of this method, however, will zero-out any actual excess power during the calibration period (first 10,080 minutes). This is normally not a major problem for larger palladium electrodes because at least one week of electrolysis is usually necessary before the excess enthalpy developes. ${ }^{7,8}$ In this experiment, there were no signs of excess power for the small palladium particles during the first week of electrolysis such as any unusual decreases of the lower-bound heat transfer coefficients.

Figure 1 shows a schematic of the fluidized-bed electrochemical cell. Preliminary studies showed that these particles were too heavy to be suspended in solution by the deuterium gas evolution and that only the surface layer particles showed movement during electrolysis. Therefore, this electrochemical cell would actually be a closer fit to a packed-bed electrolyzer. ${ }^{1}$ 


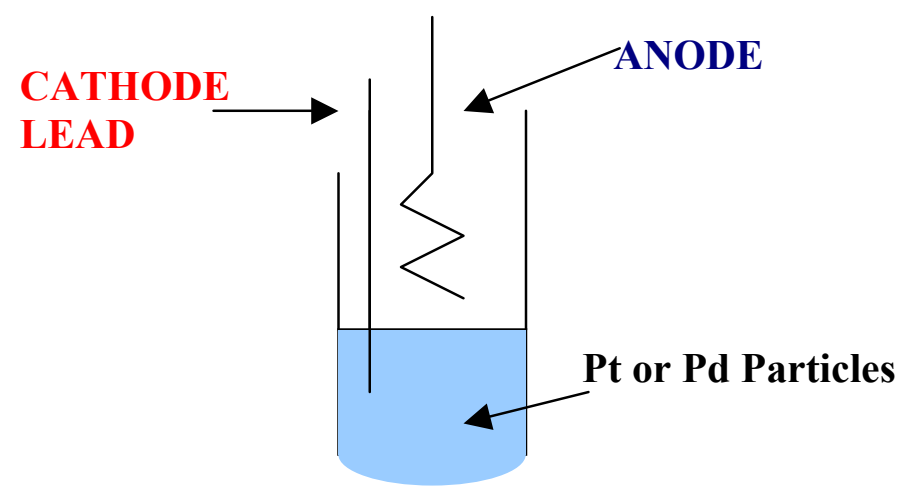

Figure 1. Electrochemical cell containing platinum or palladium particles.

The bottom of each electrochemical cell was filled to a level of 3 to $4 \mathrm{~mm}$ with a small metal particles. A platinum wire sealed in shrink Teflon with only a small tip exposed was used to make electrical contact to the metal particles at the bottom of the cell. A platinum coil anode was positioned about $0.5 \mathrm{~cm}$ above the bed of metal particles. Each cell was filled with $18.0 \mathrm{~mL}$ of $\mathrm{D}_{2} \mathrm{O}+0.1 \mathrm{M}$ LiOD. Two thermistors were fixed in position on the outside surface of each cell as described in previous experiments. ${ }^{3}$

\section{Pulse Power Electrolysis}

Extreme conditions can be produced at electrode surfaces by the use of pulse electrolysis methods. Figure 2 shows the cell voltage and cell current versus time for a typical pulse applied to these cells containing platinum or palladium particles

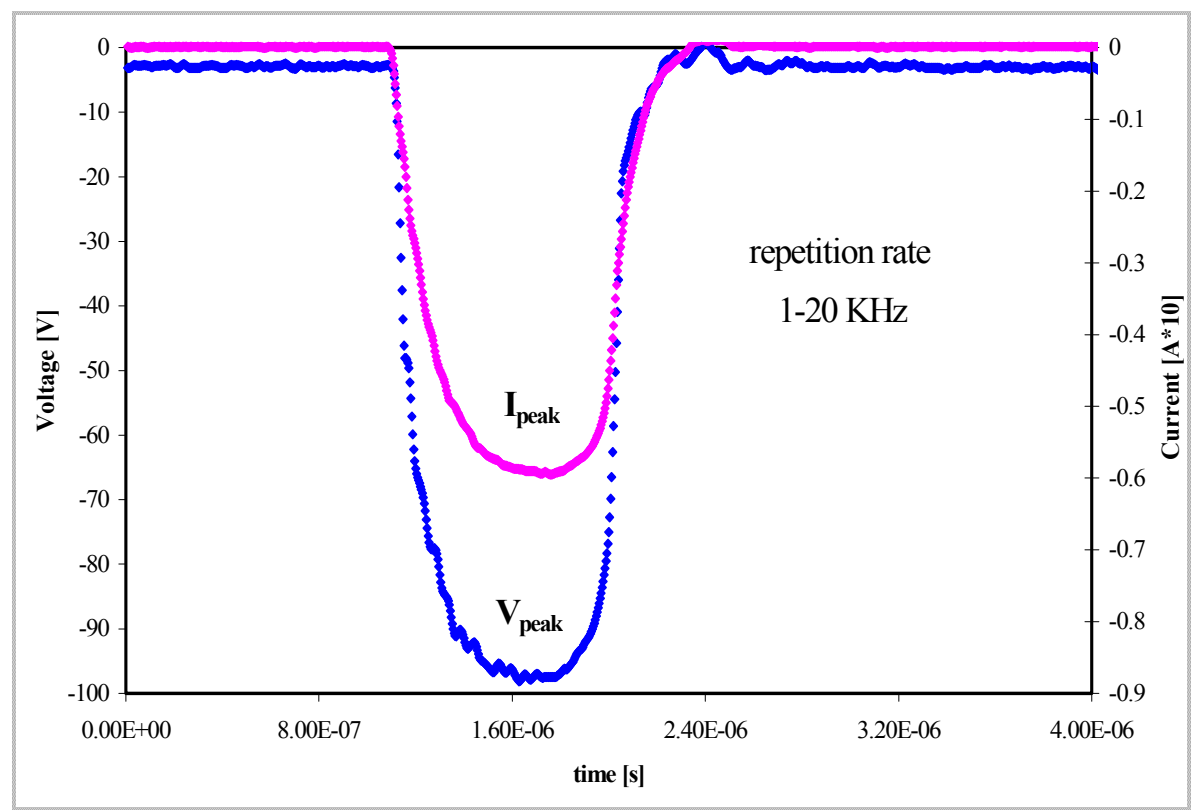

Figure 2. The cell voltage and cell current response for a typical pulse (pulse width of $1.0 \mu \mathrm{s})$. 
For the electrolysis pulse shown in Figure 2, the peak cell voltage reaches $98 \mathrm{~V}$, the peak current is $6.0 \mathrm{~A}$, and the pulse width is $1.0 \mu \mathrm{s}$. The potential of the cell can be expressed by

$$
E_{\text {cell }}=E_{o c}+\eta_{A}+\eta_{C}+I R
$$

where $E_{o c}$ is the open-circuit potential $(I=0), \eta_{A}$ and $\eta_{C}$ are the over-potentials at the anode and cathode, respectively, and $I R$ is the voltage contribution due to the ohmic resistance $(R)$ of the cell. The $I R$ contribution to the cell voltage is established almost instantaneously followed more slowly by the kinetic (activation) and diffusion (concentration) over-potentials at each electrode. The shape of the current and voltage curves versus time (Figure 2) suggests that the $I R$ term in Equation 1 is the main contributor to the cell voltage. The cell resistance $(R)$ is estimated to be 10-15 ohms based on Figure 2 results.

The pulse frequency (repetition rate) was varied from 1 to $20 \mathrm{kH}_{\mathrm{Z}}$, but the frequency of $5.0 \mathrm{kH}_{\mathrm{Z}}$ was often used. At this frequency, the electrolysis pulse is applied for only $0.50 \%$ of the time, and the cell is off $99.5 \%$ of the time. Therefore, the average electrolysis current was generally only about $12 \mathrm{~mA}$, and the $\mathrm{D}_{2} \mathrm{O}$ solution levels decreased very slowly over time during pulse electrolysis.

The average electrolysis input power to the cell requires the summation over all data points in the pulse (Figure 2) using the equation

$$
P=\Sigma\left(E_{i}-E_{H}\right) I_{i} \Delta t_{i} \bullet f
$$

where $\Delta t_{\mathrm{i}}$ is the pulse width $(s)$ and $f$ is the frequency of the pulse $(H z)$. The thermoneutral potential $\left(E_{H}\right)$ must be subtracted from each cell voltage measurement $\left(E_{i}\right)$. This precisely corrects for the reaction enthalpy $(\Delta H)$ contained in the $\mathrm{D}_{2}$ and $\mathrm{O}_{2}$ electrolysis gases escaping from the cell. From Kirchoff's Law that gives the temperature dependence of reaction enthalpies, ${ }^{9}$ and introducing $\triangle H=-n F E_{H}$ yields

$$
E_{H}=1.5318346-0.0002067(T-273.15)
$$

for the reaction $\mathrm{D}_{2(\mathrm{~g})}+1 / 2 \mathrm{O}_{2(\mathrm{~g})} \rightarrow \mathrm{D}_{2} \mathrm{O}_{(\mathrm{l})}$. At a typical cell temperature of $50^{\circ} \mathrm{C}(323.15 \mathrm{~K}), E_{H}=1.5215 \mathrm{~V}$.

\section{Excess Power Measurements}

Figure 3 presents the experimental results for Cell A that contains the platinum particles. There is very little difference in the two lines that show the output power of the cell and the electrochemical power added to the cell, thus the excess power, $\mathrm{P}_{\mathrm{x}}=\mathrm{P}_{\text {out }}-\mathrm{P}_{\mathrm{in}}$, is close to zero. For the first two thirds of the experiment, constant current electrolysis was used for the input power. At 12945 minutes (9.0 days), the input power to the cell was switched to the pulse power mode. Figure 3 shows that there was no significant excess power for the platinum particles in Cell A at any time during this experiment. In fact, the measured output power is often slightly less than the input power. 


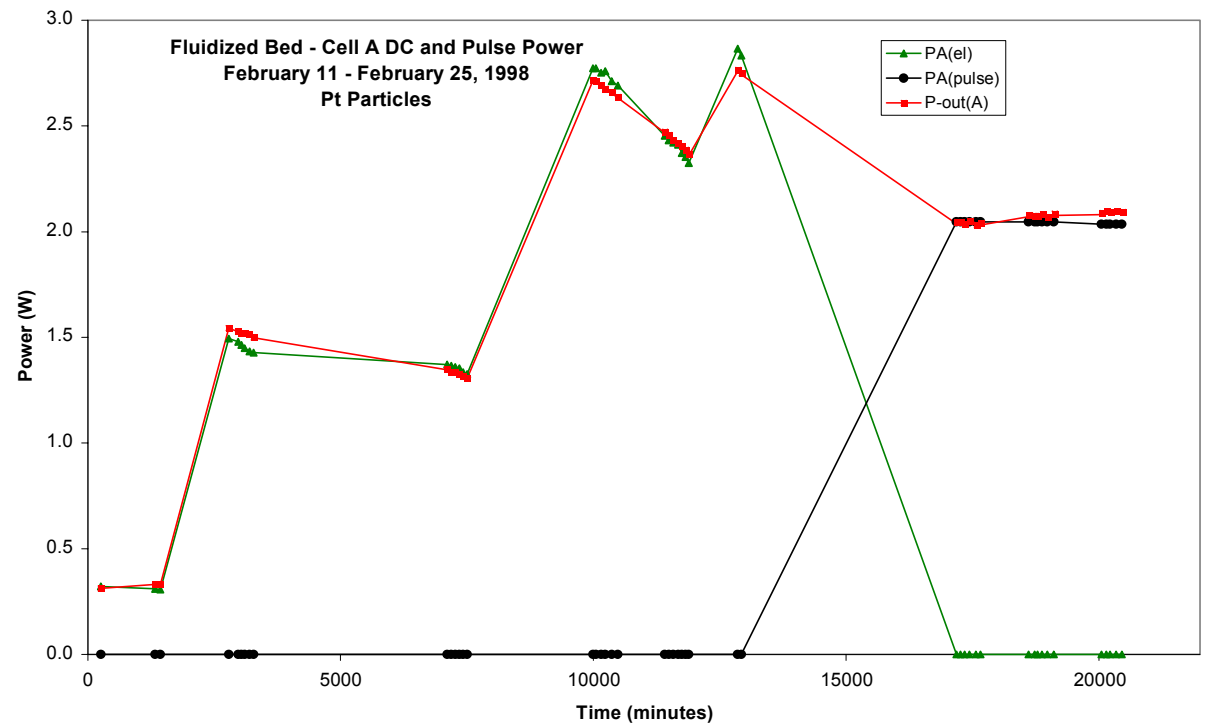

Figure 3. The electrochemical power input and the calorimetrically measure output power for the platinum particles in Cell A.

Results for the palladium particles in Cell B are shown in Figure 4. This figure shows the electrochemical power along with the output power measured calorimetrically. After about a week of electrolysis (the calibration period), the output power begins to slightly exceed the input power to the cell. The excess power reaches a peak of about $90 \mathrm{~mW}$ for the direct current electrolysis at about 17180 minutes (11.9 days) into the experiment. The electrochemical input power was switched to the pulse power mode at 20490 minutes (14.2 days). As shown in Figure 4, even larger amounts of excess power were observed using pulse electrolysis. The anomalous heat effect increased with time and reached $250 \mathrm{~mW}$ of excess power. ${ }^{10}$

Figure 4. Excess power measurements for the palladium particles in Cell B.

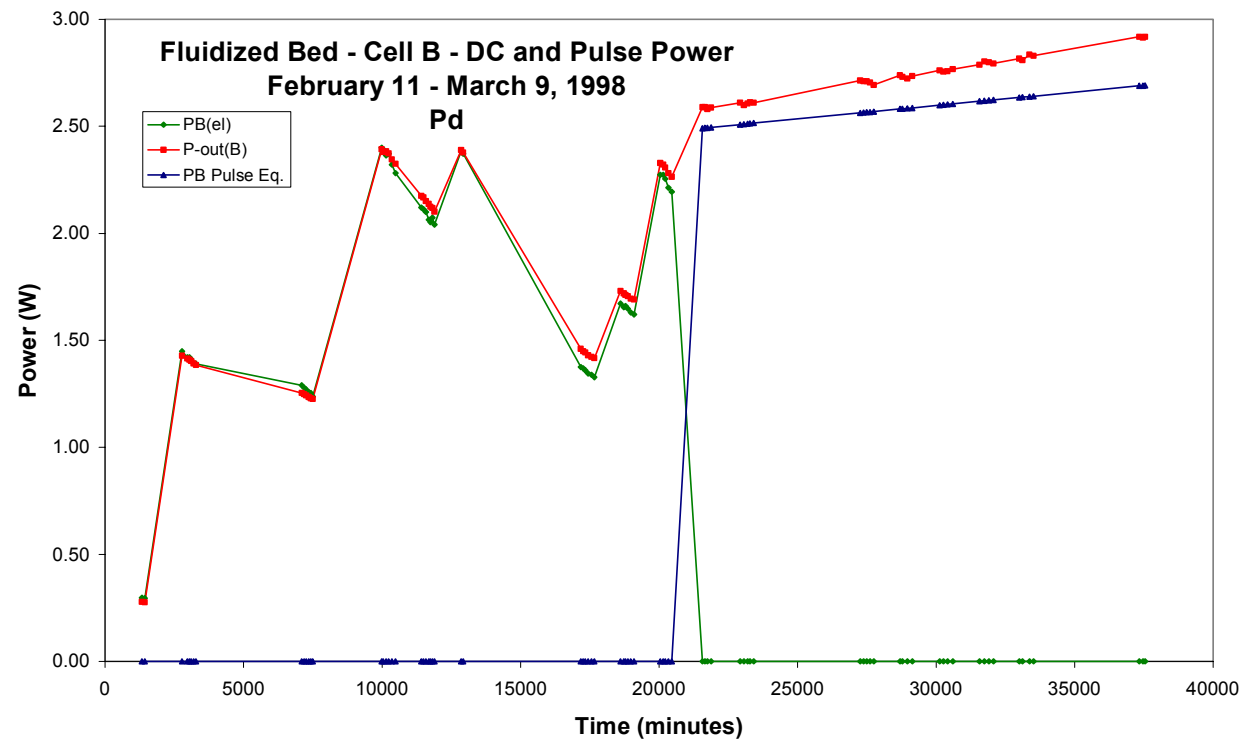




\section{Discussion}

The miniature palladium particles used in this experiment were too large to be fluidized by the electrolysis gas stream. Nevertheless, the top layer of small metal particles were observed to jostle about during the constant current electrolysis, hence new surfaces were continually exposed to the top portion of the metal/electrolyte interface. A larger agitation of the particles would be expected by the pulse electrolysis. It is likely that more and more palladium particles became involved with the electrolysis with time during the pulse experiments. This is indicated by the increase in excess power with time for the pulse method as shown in Figure 4.

The black, dendritic palladium material produced in the codeposition experiments ${ }^{11-14}$ is capable of being fluidized in $\mathrm{D}_{2} \mathrm{O}+\mathrm{LiOD}$ electrolysis experiments. If these codeposition particles become detached from the cathode, they can be observed to be suspended and move about in the solution due to the gas evolution. A future fluidized bed experiment would be to use electrochemically deposited palladium material confined in a fine wire mesh container as the cathode. Previous work has shown that the codeposition method is capable of producing excess enthalpy even at small current densities. ${ }^{15,16}$ Electrochemically deposited platinum material could be used as a control in similar $\mathrm{D}_{2} \mathrm{O}+$ LiOD solutions.

\section{Summary}

The use of small palladium particles approximated fluidized bed or packed bed reactors and produced dynamic electrolysis conditions. The excess power measured calorimetrically was $90 \mathrm{~mW}$ for direct current electrolysis and $250 \mathrm{~mW}$ for pulse electrolysis. No excess power was observed for similar experiments using platinum particles in a $\mathrm{D}_{2} \mathrm{O}+\mathrm{LiOD}$ solution as a control.

\section{Acknowledgments}

The author thanks the New Energy Development Organization (NEDO) of Japan for the appointment as a guest researcher that made this work possible. The author also thanks Dr. P. Tripodi for his assistance in the pulse electrolysis studies. The author also thanks Linda Miles for the preparation of the figures and typing the manuscript.

\section{References}

1. J. O’M. Bockris and S.U.M. Khan, "Surface Electrochemistry: A Molecular Approach", Plenum Press, New York (ISBN 0-306-44339-1), pp. 961-965 (1993).

2. $\quad$ V.S. Bagotzky, "Fundamentals of Electrochemistry", Plenum Press, New York (ISBN 0-306-443384), p. 413 (1993).

3. M.H. Miles, J. Electroanal. Chem., 482, 56 (2000).

4. M.H. Miles, B.F. Bush, and D.E. Stilwell, J. Phys. Chem., 98, 1948 (1994).

5. M.H. Miles, M. Fleischmann, and M.A. Imam, "Calorimetric Analysis of a Heavy Water Electrolysis Experiment Using a Pd-B Alloy Cathode", NRL/MR/6320-01-8526, 155 pp, March 26, 2001.

6. S. Szpak, P.A. Mosier-Boss, M.H. Miles, M.A. Imam, and M. Fleischmann in "Thermal and Nuclear Aspects of the $\mathrm{Pd} / \mathrm{D}_{2} \mathrm{O}$ System", Vol. 1, S. Szpak and P.A. Mosier-Boss, Editors, Technical Report 1862, pp. 31-89, February 2002.

7. M.H. Miles, B.F. Bush, G.S. Ostrom, and J.J. Lagowski in "The Science of Cold Fusion", ICCF-2 Proceedings, T. Bressani, E. Del Giudice, and G. Preparata, Editors, Italian Physical Society, pp. 363-372 (1991).

8. M.H. Miles, R.A. Hollins, B.F. Bush, and J.J. Lagowski, J. Electroanal. Chem., 346, 99 (1993). 
9. P. Atkins and J. de Paula, "Physical Chemistry", $7^{\text {th }}$ Edition, (ISBN 0-7167-3539-3), W.H. Freeman and Co., New York, p. 63 (2002).

10. M.H. Miles, "Bulletin of the American Physical Society", Vol. 48, No. 1, Part II, Abstract Z 33 4, p. $1382(2003)$.

11. M.H. Miles, S. Szpak, P.A. Mosier-Boss, and M. Fleischmann in "Condensed Matter Nuclear Science, ICCF-9 Proceedings", Zing Z. Li, Editor, Tsinghua University Press (ISBN 7-302-06489X), pp. 250-254 (2003).

12. S. Szpak, P.A. Mosier-Boss, J. Dea, and F. Gordon in "ICCF-10 Proceedings" (2003, in press).

13. S. Szpak, P.A. Mosier-Boss, and J.J. Smith, J. Electroanal. Chem., 302, 255 (1991).

14. S. Szpak and P.A. Mosier-Boss, Il Nuovo Cimento, 112A, 577 (1999).

15. S. Szpak, P.A. Mosier-Boss, and M.H. Miles, Fusion Technol., 36, 234 (1999).

16. S. Szpak, P.A. Mosier-Boss, M.H. Miles, and M. Fleischmann, Thermochim. Acta (accepted for publication). 